\title{
¿DÓNDE ESTUVIMOS, DÓNDE ESTAMOS Y HACIA DÓNDE VAMOS CON EL LIBRO Y LA LECTURA?
}

Bernardo Subercaseaux 


\section{BENARDO SUBERCASEAUX}

Profesor titular de la Facultad de Filosofía y Humanidades de la Universidad de Chile. Licenciado en Filosofía con mención en Literatura General de la Universidad de Chile. Magíster y Doctorado en la Universidad de Harvard. Ha sido también docente en las Universidades de Washington, Stanford y Maryland, Estados Unidos, en la Universidad de la Habana, Cuba, y en la Universidad del Rosario, Colombia. Destacado autor de libros sobre cultura chilena e hispanoamericana, entre ellos Historia del libro en Chile (2010). Es miembro del Consejo del Observatorio del Libro y la Lectura. 


\section{¿DÓNDE ESTUVIMOS, DÓNDE ESTAMOS Y HACIA DÓNDE VAMOS CON EL LIBRO Y LA LECTURA?}

\section{UTOPÍA Y REALIDAD}

Cuando en 1811 llegó la primera imprenta a Chile, Camilo Henríquez la bautizó como la "máquina de la felicidad"; "está ya en nuestro poder — escribió- el precioso instrumento de la Ilustración Universal... Los sanos principios, el conocimiento de nuestros eternos derechos, las verdades sólidas y útiles van a difundirse entre todas las clases del Estado... la voz de la razón y de la verdad se oirán entre nosotros después del triste e insufrible silencio de tres siglos". Son frases hiperbólicas que conllevan una veneración por el libro y la educación concebidos como la panacea para la emancipación mental. Frases que implican una política pública sobre el libro y la lectura. ¿Pero de qué libros se trataba? ¿Estaba pensando Camilo Henríquez en libros religiosos o de entretenimiento? La perspectiva religiosa está completamente ausente en La Aurora de Chile. El Fraile de la Buena Muerte era contrario al uso y enseñanza del latín, por entonces idioma oficial de la Iglesia. Henríquez no estaba pensando, por ende, ni en vidas de santos, ni en devocionarios, ni en almanaques u otros géneros livianos provenientes de España. Pensaba, como señala en varios de sus escritos, en "libros útiles o morales" (así se decía en la época): libros proveedores de conocimiento, que contribuyeran al ejercicio de la razón, al pensamiento autónomo y crítico, a la formación y sensibilidad estética, al desarrollo de una actitud republicana en la perspectiva de los ideales ilustrados y liberales. En el mundo real, sin embargo, lo que ocurría distaba mucho de las posibilidades para implementar esa utopía. Eran ideas fuera de lugar. La aletargada sociabilidad colonial seguía operando. Apenas el 10 \% de la población del país sabía leer. John Miers, ingeniero inglés que estuvo en Chile varios años a partir de 1818, refiriéndose a la educación en esa década escribió lo siguiente: "Los chilenos son ignorantes, y proclaman con cierto orgullo que no requieren del conocimiento de los libros. Tienen además muy pocos y los pocos que tienen no los leen".

Esta disparidad entre una veneración excesiva y casi fetichista del libro y la lectura, concebidos como vehículo privilegiado de la educación por un sector de la élite y, por otra parte, un desinterés por los libros y la lectura en sectores muy amplios de la sociedad, se mantiene hasta el día de hoy. En la cápsula que se enterró en la Plaza de Armas a propósito del Bicentenario (con presencia del presidente Piñera y sus ministros) la elección de los personajes más representativos de nuestra identidad —elegidos por votación digital y popular - recayó en Don Francisco y en el perrito de Lipigas, en personajes del espectáculo y la publicidad, y no en Neruda, ni en Gabriela Mistral, ni en Violeta Parra. A todos ellos les ganó incluso el Indio Pícaro. 
A propósito de la reciente elección de títulos por los directores de 450 bibliotecas públicas del país, realizada en la última Feria del Libro, ejemplares que serían adquiridos por el Estado para esas bibliotecas, llamó la atención que entre los diez títulos más requeridos figurasen dos biografías de Felipe Camiroaga y varios bestsellers. Libros de farándula y diversión, libros de tinte más bien escapista. Situación ésta que dio pie a un debate: ¿Qué libros y qué lectura debe fomentar el Estado? ¿Aquella que duplica lo que entregan periódicos faranduleros o chismografías televisivas disfrazadas de glamour? ¿O acaso, de preferencia, bestsellers de entretención? ¿No debiera ser el mercado el que provea esas demandas? De hecho, así ocurre con los libros de yapa que obsequian o venden a muy bajo precio periódicos y revistas, o con los libros vendidos en kioscos y, a veces incluso pirateados, en las aceras. Pero, por otra parte, si los directivos de bibliotecas que seleccionaron los títulos hubiesen elegido mayormente libros clásicos, libros históricos, científicos o formativos, ¿quién los habría leído? Serían probablemente libros no consultados, libros sin lectores, estanterías convertidas en tumbas. Hace 150 años, Domingo Faustino Sarmiento, refiriéndose a las "bibliotecas populares", creadas por él siguiendo el ejemplo de Benjamín Franklin, reflexionaba a propósito del fracaso de las mismas:

"Se pueden suministrar al pueblo libros morales" y útiles... "modelos de pureza de lenguaje", sin embargo, a ese "pueblo no puede llevársele por la fuerza y maniatado a la biblioteca, a leer lo que nada le mueve a leer. ¿Es moral el libro, es serio, es útil? Razón de más para no leerlo. El pueblo, es decir, el que no tiene el hábito de leer, comienza a leer uno de esos libros tan recomendados y principia por bostezar y acaba por dormirse" (Sarmiento, 1866).

Tanto en el pasado como en el presente son situaciones que grafican la inadecuación entre un racionalismo modernizador, que pretende formar ciudadanos pensantes y plenos, y una sociedad — ayer mayoritariamente analfabeta y hoy de masas — una sociedad que estaba - y está-, como se dice, "en otra". Se trata de un desajuste que debe hacernos reflexionar y que incide en la pertinencia o no de políticas públicas de largo aliento sobre el tema. ${ }^{1}$ Plantea también la cuestión de qué tipo de políticas sobre el libro y la lectura se requieren.

Si contemplamos el siglo XIX resulta claro que el pensamiento y los planteamientos de la élite ilustrada post Independencia eran impracticables, puesto que carecían de suelo histórico. Sin embargo, paradojalmente, eran también indispensables. Formulados en el aire y sin piso, pero con fe ideológica, esos planteamientos dieron pie a una verdadera posta de ideales que poco a poco fueron siendo posibles. Primero, la generación de la Independencia, con figuras como Camilo Henríquez, Juan Egaña y Manuel de Salas, luego la generación de 1842, con Lastarria y con figuras transversales como Bello y Sarmiento, y luego los positivistas y los grandes educadores republicanos de fines del XIX, como Valentín Letelier. Ideales en un comienzo quiméricos, pero que de modo paulatino — con la creciente alfabetización, la conformación del Estado Docente y el aumento de las capas medias - fueron convirtiéndose en una realidad, hasta que, a mediados del siglo

1. Sobre esta disparidad véase Schwarz, R., "Las ideas fuera de lugar" en CEBRAP, 3, Sao Paulo, 1973, pp. 13-28. 
XX, el imaginario del libro y la lectura llegó a ser socialmente valorado como instancia de ciudadanía, de identidad cultural y de movilidad social. La utopía de Camilo Henríquez resultó a la larga, entonces, "en alguna medida", una verdad prematura. ¿Pero qué debió acontecer para que ello ocurriera? Fue necesario un cambio del suelo sociocultural, un proceso de transformación gradual de la sociedad, transformación que en sentido estricto no está en el ámbito específico de las políticas institucionales del libro y la lectura, sino de una política más amplia de progreso e inclusión social.

Decimos "en alguna medida" debido a que el siglo XIX no fue en Chile, ni menos en otras regiones de América Latina, una etapa plena de inclusión social. Tal como lo diagnosticó Alejandro Venegas en Sinceridad. Chile íntimo, en 1910 quedaba casi todo por hacer en términos de democracia republicana, de educación e inclusión social. La constatación de esta debilidad decimonónica en la construcción de las naciones se hizo patente en varios países.

Ya a fines del siglo XIX, en un ensayo de José Martí (Nuestra América, 1891) emerge una matriz crítica sobre la colonización mental y cultural que ha operado en el continente, élites ilustradas que desconocían la diversidad cultural y que repetían como loros las ideas, libros y costumbres europeas. "Nuestra Grecia — proclamó Martí, refiriéndose a las culturas precolombinas- es preferible a la Grecia que no es nuestra", ironizó también sobre los letrados artificiales, aquellos que sienten vergüenza del delantal de su madre india, y que en lugar de mirar la realidad de sus propios países viven pendientes de lo que ocurre en Europa. La supuesta universalidad ilustrada y liberal que jurídicamente se suponía operante, disfrazaba una realidad de inequidades y una marcada exclusión y discriminación social. Se trata de una matriz crítica que ha tenido continuidad en destacados intelectuales de países con alta población indígena, autores como Miguel Ángel Asturias en Guatemala, José María Arguedas en Perú y Augusto Roa Bastos en Paraguay, autores que tematizando sus circunstancias locales se hicieron cargo del patrimonio conflictivo de América Latina, de una realidad que por un lado fue obra modernizadora de espíritu renacentista e ilustrado y por otro apocalipsis e invisibilidad de las culturas autóctonas. Son autores que, a través del soporte libro, rescatan y vivifican las culturas orales de los pueblos originarios, mediante — como lo vislumbró Ángel Rama— un proceso de transculturación narrativa.

Esta matriz crítica también está presente en los modernistas brasileños ("Tupí or not tupi, that is the question") $)^{2}$, y en pensadores como el propio Ángel Rama en La ciudad letrada (1984) o en disciplinas como la antropología latinoamericana. Antropólogos como el brasileño Eduardo Viveiros de Castro, conciben su disciplina como una lucha en pro de la autodeterminación de las minorías étnicas, sometidas y colonizadas desde el siglo XVI. Según Viveiros de Castro, "saber leer no va a volver (a una persona) más inteligente que un habitante de un mundo oral que sabe pensar por sí mismo". ¿Es que estos autores son acaso antilibros o anti cultura ilustrada europea? No, todo lo contrario,

2. Frase del Manifiesto antropófago (1928) de Oswald de Andrade, que celebra la etnia Tupí y, simultáneamente, el canibalismo de Shakespeare, planteando la antropofagia de la cultura occidental como una estrategia anticolonial. 
son ensayistas cultos en el sentido occidental y cultos también en el sentido americano (sobre todo Arguedas y Viveiros), pensadores creativos y amantes como pocos de los libros y que, además, expresan sus ideas y obras por vía de ese soporte; lo que sí subyace a sus planteamientos es que el libro y la lectura no pueden ser solo formas ornamentales de la modernidad, y que la disociación entre el suelo sociocultural y la utopía ilustrada debe ser orgánicamente acoplada, lo que solo es posible con políticas de inclusión de largo aliento (según Martí, "la República que no es de todos no es República"). Lo que requiere de una educación con acceso generalizado, que incorpore y se apropie de la cultura universal pero que, al mismo tiempo, respete y "salvaguarde" (es la palabra que usa José Martí en Nuestra América) el tronco y la raíces culturales autóctonas.

En definitiva, las políticas del libro y la lectura promovidas por el Estado, en la perspectiva que al Estado y al bien común interesa, deben ir acompañadas por una decidida política de inclusión social, una política que tenga como uno de sus pilares una educación humanista, científica y técnica de calidad, pero también abierta, diversa y atenta a las particularidades y al espesor cultural de las distintas etnias y sectores del país. En una perspectiva de tiempo largo, este se vislumbra como el único camino para acortar la distancia entre la utopía ilustrada y el suelo histórico, entre la oferta y la demanda. Sin esa precondición, los "maletines literarios", por muy bien intencionados que sean, corren el riesgo de ser recursos dilapidados.

Cabe señalar, además, que la utopía ilustrada de hoy, aunque arrastra huellas de la utopía decimonónica, no puede ser la misma y debe ajustarse al siglo XXI, a los cambios tecnológicos, a la hiperinflación de la cultura de masas, al avance de la imagen sobre la palabra y al ejercicio de su propia autocrítica.

\section{UNA MIRADA HISTÓRICA}

De lo señalado podría colegirse que mientras la disociación entre utopía y realidad no se acorte, mientras no se produzca una transformación profunda de la sociedad, las políticas institucionales sobre el libro y la lectura serían inútiles: un puro voluntarismo carente de suelo histórico. Como lo muestra un breve examen comparativo con otros países hispanoparlantes, se trata de una presunción errada y, aun más, falsa.

Tal como detallamos en nuestra Historia del libro en Chile (Subercaseaux, 2011), la época de oro del libro chileno fue entre 1930 y 1950: editoriales como Zig-Zag y Ercilla ofrecían catálogos diferenciados en distintos países de Hispanoamérica; Zig-Zag en 1941 exportó 260 mil libros y en 1943 más de 200 mil. Ercilla tenía sucursales o representantes en Argentina, Cuba, Colombia, México y Uruguay. Incluso editoriales más pequeñas como Nascimento y Cultura tenían presencia y distribución en distintos países del continente. "Chile empezaba a ser un centro editorial. Publicaba mucho, aunque mal", recuerda en sus Memorias el peruano Luis Alberto Sánchez. A raíz de la crisis de 1929 se produjo un cierre de las fronteras económicas, restringiéndose la importación de libros, lo que estimuló la producción nacional. Luego, tal como señala un catálogo de la Editorial Splendor, "la guerra civil española, primero, y la actual guerra 
mundial después, han cerrado, se puede decir, las fuentes de producción del libro, de donde se surtían los libreros, y esto ha dado lugar a la formación de editoriales" locales, "que cada día aumentan su producción y mejoran su calidad, supliendo en gran parte la escasez de libros" importados; contexto este que — sumado al hecho de que las industrias argentina, mexicana y española solo despegan después de 1950— favorecía ampliamente las posibilidades del libro chileno. También hay que señalar que el Frente Popular y el Estado de compromiso, con los gobiernos radicales a la cabeza, apoyaron la educación pública y la presencia de capas medias letradas, constituyendo un mercado interno significativo, en años en que en casi todos los livings de las casas había estantes con libros. Fueron años en que la lectura, el liceo y la universidad pública eran parte sustantiva de la identidad mesocrática y de la movilidad social, el libro portaba entonces una valoración social de la cual hoy día carece. Recuerdo incluso que yo mismo, que viví en la década del 60 la cola de ese proceso, en una época en que no se usaba mochila, cambiaba diariamente los libros que llevaba a la universidad, con afanes de conquista de alguna estudiante.

Entre 1930 y 1950 se vivió, en síntesis, un panorama alentador para el libro chileno con proyección internacional, un mercado interno activo y con diversidad de intereses, una oferta abundante de títulos relativamente baratos, que llegaban a los lectores a través de distintos puntos de venta. Además, una posición relativamente aceptable en cuanto a insumos (papel, tintas) y parque impresor. Una situación que se vislumbraba expectante, puesto que ofrecía ventajas comparativas para transformar al país en una potencia editorial a nivel latinoamericano e hispanoparlante. Una situación que, sin embargo, sufrió en las décadas siguientes una atrofia y hasta una involución. ¿Qué ocurrió? ¿Cómo se explica ese estancamiento?

Terminada la guerra, los mercados europeos y norteamericanos recuperaron su normalidad. Resultaba imposible para Ercilla o Zig-Zag publicar o traducir sin cancelar los derechos legales. Por otra parte, la Ley de Renta obligó a las editoriales locales a pagar un impuesto adicional, que se tradujo en un recargo del $60 \%$ sobre el pago de derechos de autor, por lo tanto, resultaba prohibitiva la adquisición de títulos en el mercado internacional. Sin embargo, lo más decisivo es que mientras el libro en Chile resultaba castigado, en Argentina, México y España se establecieron políticas de fomento estatales con un sistema completo de beneficios para el sector privado. Leyes que contemplaban exenciones tributarias, créditos preferenciales de expansión e importación, fomento a la exportación, beneficios arancelarios, subvenciones, libre ingreso de materia prima y maquinarias, tarifa postal bonificada, trato preferencial a las librerías, etc. Gracias a esas políticas de fomento el mercado hispanoparlante fue poco a poco copado por la industria editorial argentina primero, luego la española y la mexicana, y últimamente también por la colombiana, país que desde 1973 cuenta con una ley que ha dinamizado el sector. Son políticas de fomento que inciden en toda la cadena del libro, desde la producción hasta la lectura, también en premios y estímulos a los autores, en traducciones al extranjero, en una participación destacada y con apoyo estatal en ferias internacionales y también — comparativamente con Chile— en precios de venta más bajos. Nada de eso ocurrió en nuestro país: en un contexto en que el empresariado nacional subordinaba su 
iniciativa a la protección y al sostén crediticio estatal, la industria editorial chilena y toda la cadena del libro, al no contar con el amparo de una política de fomento y siendo más bien una actividad castigada (sobrecarga impositiva, insumo fundamental en manos de una empresa única, etc.) entró en una etapa de franco estancamiento. Las grandes editoriales como Ercilla, o algunas más pequeñas pero significativas, como Nascimento y Cultura, languidecieron hasta desaparecer.

El rol activador del Estado en varios países si bien no solucionó definitivamente la distancia entre la utopía del libro y el suelo social, si contribuyó a disminuir ese desfase y a aumentar los índices de lectura, lo que demuestra que las políticas públicas específicas para el libro y la lectura son necesarias y no inútiles. Aún más, si esas políticas se hubiesen implementado en nuestro país hacia 1950, cuando incluso la CORFO era la instancia adecuada para ello, toda la situación del libro y la lectura tendría en el Chile de hoy otro perfil.

\section{CONTEXTO}

Otro factor que ha incidido en las políticas públicas sobre el libro ha sido el contexto político e histórico social. Entre 1970 y 1973, en el ámbito de la cultura, el proyecto de la Unidad Popular se propuso por una parte democratizar los bienes culturales, en términos de distribución y acceso y, por otra, activar la democracia cultural, la participación de distintos y variados agentes en la vida cultural. Dentro de esta perspectiva, debido a un conflicto laboral y a una demanda de estatización por los trabajadores de Zig-Zag, se dio una negociación entre el Estado y los dueños de esa empresa a través de la cual el Estado pasó a ser propietario de todo el aparato impresor de una de las editoriales más antiguas y significativas del país. El Estado, con representación de los partidos políticos que participaban del Gobierno, creó la Editorial Quimantú. A la vuelta de un par de años esta editorial realizó una masificación del libro inédita en el país, publicando varias colecciones en tirajes de 30, 50 y hasta de 100 mil ejemplares. Paralelamente a las librerías, Quimantú montó un sistema de distribución con visitas a centros universitarios y laborales a lo largo de todo Chile. Colecciones periódicas como Nosotros los chilenos y Quimantú para todos se vendían en los kioscos. Aun cuando la gestión de esta empresa estatal experimentó las dificultades propias de la sobrepolitización del país, no cabe duda que incrementó la presencia del libro y la lectura en amplios sectores sociales. Fue, sin embargo, una masificación del libro que quedó trunca, por una parte porque no se elaboró una política de fomento para el sector en su totalidad y, por otra, porque cada vez más un espectro amplio — sobre todo de sectores medios y altos_- percibió a Quimantú como un aparato cultural al servicio de "doctrinas foráneas", como un aparato que debía ser sofocado e inhibido, tal como efectivamente lo fue a pocos días del golpe militar del 11 de septiembre de 1973.

A partir de esa fecha el contexto político se expresó en una involución de la cultura y del sector del libro. Partió con la quema de ejemplares y con un clima de amedrentamiento hacia cualquier lectura que pudiese considerarse "subversiva", aunque fuese un 
libro sobre el Cubismo en la pintura. Este clima se sancionó inicialmente mediante una política represiva que afectó a librerías, autores y títulos, y luego con un régimen de censura previa que se prolongó por 10 años hasta junio de 1983. Pero aún después, hasta fines de la dictadura, el clima anti libro se mantuvo, dirigido fundamentalmente contra los libros que Camilo Henríquez y Sarmiento llamaban "libros útiles o morales". En La Nación (31-05-1984), entonces diario de Gobierno, a propósito del día internacional del libro se publicó el siguiente editorial:

"El acto de regalar un libro, tan simple en apariencia, tan inofensivo, envuelve riesgos que no se pueden pasar por alto. No siempre un libro, por el solo hecho de serlo satisface el propósito ideal que generalmente le suponemos. Porque no siempre resulta ser un agente confiable de cultura o un recurso no contaminado de salud mental. A veces, más a menudo de lo que quisiéramos, encontramos libros que so pretexto de divulgar teorías novedosas desvirtúan el recto juicio de las cosas o ensucian el cauce limpio y natural de la verdad".

Cabe recordar que cuando a mediados de la década del 80 empezó a circular en el país Confieso que he vivido, las memorias póstumas de Neruda, El Mercurio publicó un artículo sobre ella con el título de una obra del dramaturgo novohispano Juan Ruiz de Alarcón: La verdad sospechosa. Es posible conjeturar que si en 1973 hubiese estado operando la cadena del libro al amparo de una política de fomento y con presencia en el mercado internacional, el clima de inquisición y control habría tenido características diferentes.

En suma, lo señalado indica que los climas políticos e históricos tienen implicancias, a veces directas y otras indirectas, en el libro y la lectura. También, que la carencia de políticas de Estado de largo plazo afecta al mundo del libro y a la demanda, ya sea por la vía del estímulo y la activación, en un caso, o del amedrentamiento y desactivación, en el otro.

\section{PRESENTE Y FUTURO 3}

En la perspectiva de reactivación del libro y la lectura, y de una política pública integral que contribuya decididamente a ello, cabe un diagnóstico también integral de la situación actual:

1. ¿Es Chile un país lector? Diversos estudios revelan más bien que no y apuntan a problemas de arrastre en la educación en todos sus niveles. Una encuesta sobre hábitos de lectura realizada en las 16 principales ciudades del país por Adimark para la Fundación La Fuente, en mayo y junio del año 2006, determinó que un 45\% de

3. En esta sección recurro a datos y antecedentes utilizados en Subercaseaux, B., "La encrucijada del libro y la lectura", en Observatorio Cultural 1, Santiago: Consejo de la Cultura y las Artes, 4-7, 2011 y Subercaseaux, B., "La industria del libro: una mirada desde Chile" en Revista Chilena de Literatura, 86, Santiago, 2014 (en prensa). Agradezco también las observaciones y sugerencias de Alejandra Bottinelli. 
los mayores de 18 años no lee libros en absoluto, y que un 34\% son lectores ocasionales. En el año 2009, el Consejo Nacional de la Cultura y las Artes, en la Segunda Encuesta Nacional de Participación y Consumo Cultural, basada en una muestra más amplia, detectó que el 59\% de los encuestados no ha leído libros en el último año, y que en el rango etario de 15 a 29 años la razón por la que no leen es, en un $41,3 \%$, porque no les interesa y, en un $28,5 \%$, por falta de tiempo. Finalmente, un sondeo realizado en diciembre del año 2009, con una muestra representativa de los residentes del Gran Santiago, reveló que un 53,9\% no ha leído ni siquiera un libro durante los últimos 12 meses. Las razones por las que no leen son, según esta encuesta, en casi un $60 \%$ la falta de tiempo y el desinterés. Se trata, en todos los estudios, de indicadores que muestran a una sociedad predominantemente no lectora (de libros), y desmotivada por esta práctica. Revelan además una baja valoración social del libro en comparación con otros medios. Las encuestas muestran también un aumento permanente en el uso de Internet (qué duda cabe de que sí somos un país lector de textos por esta vía) y en el chateo, lo que implica el peligro de que se acentúe la ya débil comprensión lectora, no solo porque los alumnos lean cada vez menos libros, sino porque aumentan la lectura de mensajes breves, mal escritos y fraccionados.

Más allá de las encuestas y los indicadores, cabe mencionar, sin embargo, que desde el año 2011 se vislumbran ciertos signos esperanzadores: un aumento de lectores en el Metro, mayor preocupación pública por el libro y la lectura (el propio Observatorio del Libro así lo demuestra) y una explosión de proyectos editoriales.

2. En cuanto al clima político, vivimos hoy día un contexto positivo para una política de fomento integral del sector. La lectoescritura y la educación como problema concitan una preocupación nacional, más allá de las distintas estrategias, tiempos o modelos que se adopten para encararlo. Hoy, como en el siglo XIX, decir libro y decir lectura es decir formación, conocimiento, ciudadanía y educación.

3. En relación al suelo histórico y a la sociabilidad, todo indica que sigue vigente el desfase a que nos hemos referido antes. Los escolares han acuñado la frase "hazla cortita", apuntando a su poca paciencia para procesos graduales de conocimiento como los que requiere la lectura, acostumbrados como están a la imagen y a las nuevas tecnologías. Incluso estudiantes universitarios suelen ser reacios a la lectura de libros, no así a la de textos por Internet. En los medios de comunicación y en términos de valoración social prima el espectáculo, la entretención y el deporte; en la hiperinflación de la cultura de masas casi no hay espacio para la cultura letrada. ¿Desinterés, manipulación o sociedad de masas? Hay distintas interpretaciones.

4. Sin duda una de las raíces de una sociedad no lectora de libros está en la educación. De hecho, la prueba SIMCE (Sistema de Medición de la Calidad de la Educación), realizada el año 2008, por primera vez evaluó las habilidades no solo de lectura, sino también de escritura de alumnos de cuarto básico arrojando resultados decepcionantes. Si bien las últimas pruebas SIMCE revelan indicadores de cierta mejoría, todavía se está muy por debajo de la mayoría de los países que integran la OCDE. Además, los resultados del SIMCE, prueba que se lleva a cabo en todo el 
país, revelan diferencias por grupos socioeconómicos, los colegios municipalizados y subvencionados tienen por lo general los peores resultados. Los expertos coinciden en que si no se lee de manera regular en los primeros años, las posibilidades de comprensión y de desarrollo de la lectoescritura son muy reducidas. Aun más, hay encuestas que ponen en evidencia que incluso un número importante de profesores son poco lectores, lo que se manifiesta a veces en exigencias de lectura inadecuadas, por ejemplo, pidiéndoles a alumnos de octavo básico que lean La última niebla, de María Luisa Bombal. Los estudiantes a nivel escolar se relacionan más que con libros con textos de estudio, rara vez entran a una librería y menos aún adquieren libros (quienes los buscan y adquieren son sus apoderados). Los textos de estudio son para ellos una suerte de compendio que relacionan con determinado nivel escolar: a los de segundo medio ya en tercero no les sirven, o quedan para el hermano chico. Para los estudiantes secundarios, los libros encarnan una tarea y una obligación que requiere tiempo y paciencia (que es precisamente lo que Internet y los videojuegos les acostumbra a no tener). Leer un cuento o una novela es - con pocas excepciones- casi un castigo. Puede afirmarse, en síntesis, que a nivel escolar, en términos generales de país (considerando también que hay excepciones), no se ha desarrollado una estrategia inteligente y novedosa como la que se requiere para promover la lectura a lo largo del proceso escolar, desde el niño, pasando por el adolescente y hasta el adulto.

5. A nivel de educación básica y media, el área curricular de Lenguaje y Comunicación vigente presenta problemas tanto en el programa como en los textos escolares, que pecan en general de un carácter marcadamente instrumental y pragmático, y no están centrados en inculcar desde pequeños y a lo largo de todo el proceso escolar el hábito y el gusto por la lectura.

6. ¿Dónde está hoy día, en el año 2014, el público de lectores posibles y potenciales? Fundamentalmente, en las universidades. Es en la etapa de la universidad cuando se suele iniciar una relación personal y más permanente con los libros. Son los años en que se entra a las librerías, aunque sea de libros usados, se visitan por necesidad o interés las bibliotecas, se piden libros y se los hojea, y en el mejor de los casos se los descubre y apropia, se empieza a leer por vocación o placer, y hasta ocurre que algunos estudiantes inician una pequeña y rudimentaria biblioteca personal. ¿Qué pasa entonces con la población universitaria y los libros?

En las últimas dos décadas la población universitaria ha aumentado exponencialmente. Se estima que para el 2014 la matricula bordea un millón cien mil estudiantes. Los libros son (todavía) el soporte por excelencia de todas las carreras que se estudian en la universidad, de las disciplinas científicas y técnicas (Física, Química, Medicina, Ingeniería, Agronomía, Biología, etc.); también de las disciplinas sociales y humanistas (Jurisprudencia, Ciencias Políticas, Antropología, Psicología, Historia, Filosofía, Letras, Lingüística), sin mencionar su importancia como soporte de cultura general y de expresión literaria y poética. Aun considerando que hay universidades de primera, de segunda y de tercera, algunas acreditadas y otras que no lo están, universidades con grandes bibliotecas patrimoniales y otras con solo 
centenares o unos pocos miles de libros, aun considerando estas diferencias, es posible pensar que cada estudiante universitario debe (o debiera) leer en promedio 20 libros al año, lo que da — considerando la matricula actual— sobre 20 millones de libros por año.

Se trata de una cifra superior al número de libros que se editan cada cuatro años en el país. Corresponde sí a una cifra virtual, a un nicho de mercado posible pero que no es real. Lo que ocurre en la práctica es muy diferente. Los estudiantes universitarios en su abrumadora mayoría no leen libros, leen fotocopias, capítulos, secciones, fragmentos, artículos, hojas sueltas bajadas por internet. En definitiva, libros que no alcanzan a ser libros y que son solo textos.

La relación con semilibros, o con lonjas de libros, implica carencias de distinta índole. Es como amarse por correo electrónico: el alma se transmite, pero el cuerpo no. Se trata de una mengua que también afecta a la industria y al mercado del libro, y que termina por empobrecer la oferta editorial. Tiene además un efecto "educativo", en el sentido de que desincentiva la curiosidad intelectual. La solución no es fácil. Desde el punto de vista de los estudiantes, la fotocopia "salva", como dicen ellos. También, seguramente, "salva" a los padres. Pagando aranceles y manutención, comprar los libros que necesitan sus hijos — aunque sean usados- les resulta una quimera. Desde el punto de vista de las universidades (sobre todo de las universidades privadas que tienen propósitos mercantiles), tener bibliotecas actualizadas con el número suficiente de ejemplares para una matrícula que aumenta año a año, no parece ser un tema prioritario. Desde el punto de vista de los profesores, dar una bibliografía indicando el número de páginas a leer resulta más operativo y da mayores garantías de cumplimiento que si el alumno tuviese que adquirir o pedir en préstamo el libro. Desde el punto de vista de las editoriales, libreros y distribuidores, la fotocopia - la reprografía, así la llaman- los perjudica y obstaculiza el crecimiento y desarrollo del mercado. Una solución parcial es llevar a cabo lo realizado en países como Noruega, en que cada fotocopia paga un derecho que es recopilado por un ente independiente, derechos que van a dar a la industria editorial y a los autores. Por esta vía se puede, con el tiempo — si se adoptan otras medidas que fortalezcan la industria nacional-, lograr una baja importante en los precios y una mayor oferta de títulos, transformando así a la población universitaria en un público lector real de libros.

Los estudiantes universitarios también leen textos electrónicos. Con frecuencia lo hacen por una motivación informativa o funcional, para obtener referencias, datos o información. Cada vez más esta clase de lectura funcional se realiza en textos electrónicos a través de Internet; varias editoriales utilizan el soporte electrónico para sus enciclopedias, diccionarios o libros de referencia, también para obras en general. Hay quienes perciben en el libro impreso un medio obsoleto y en retirada, argumentan que los bancos de datos y las máquinas de búsqueda tipo Google tienen hoy día, como fuente de información y ayuda, considerable mayor capacidad de almacenamiento y rapidez que el libro. El problema es que este tipo de comparaciones descansa a veces en una premisa errada: aquella que presupone una equivalencia entre información y conocimiento. 
7. El paisaje editorial actual es diverso y complejo, y opera en un mercado pequeño, muy centralizado en Santiago, la capital, y en el que la exportación de libros comparada a otros países del continente es casi nula. Se publica un promedio real que bordea los 3000 títulos anuales en la última década, de los cuales entre un 12 a 14\% son autoediciones. Lugar preponderante ocupan cinco o seis filiales de grandes conglomerados transnacionales. Son filiales que operan con autonomía, pero con férreo control financiero de la casa matriz, lo que les obliga a publicar de preferencia libros que sean bestsellers o "sandías caladas". También forman parte de este paisaje 45 editoriales nacionales independientes que publican entre 20 y 90 títulos anuales, son editoriales que se arriesgan publicando géneros que no abordan las transnacionales, como la poesía, el ensayo y los estudios académicos. Completan el paisaje unas 45 microeditoriales surgidas en los últimos años. Publican entre uno y 15 títulos al año que en conjunto contribuyen decididamente a la expresividad social, cultural y patrimonial. En su mayoría son autogestionadas por colectivos de jóvenes que no sobrepasan los 35 años. En general, estos tres sectores tienen intereses diversos y se agrupan las primeras en la Cámara Chilena del Libro, los editores independientes en Editores de Chile, Asociación de Editores Independientes, Universitarios y Autónomos y las microeditoriales en el colectivo La Furia del Libro. Debido a que el primer sector opera con una perspectiva eminentemente mercantil y los otros dos con una perspectiva más bien cultural, a menudo han tenido posturas diferentes respecto a una política de fomento. Cabe señalar, sin embargo, que en los últimos años, entre las dos más importantes asociaciones gremiales — la Cámara Chilena del Libro y los Editores Independientes- se han logrado algunos acuerdos en los que también ha participado La Furia del Libro. Casi 100 editoriales representan —para un mercado pequeño como el chileno- un enorme potencial, si se les da aire para que respiren y se expandan. ¿Qué propuestas se pueden plantear a este respecto? Entre otras: apoyo a la internacionalización (vale más exportar libros que rollizos de pino); compras para las bibliotecas públicas en la perspectiva de la bibliodiversidad, y con promoción de los autores; ferias conjuntas; perfeccionar la Ley de Donaciones Culturales pensando en el libro y la lectura.

8. La centralización del mercado del libro en Santiago en términos editoriales se proyecta en toda la cadena del libro. Hay ciudades importantes, incluso universitarias como Valdivia y Antofagasta, que prácticamente carecen de librerías dedicadas únicamente al rubro de los libros. Hay que proponer un cauce para ir resolviendo esta aberración que significa que una población como la de Antofagasta, la "Perla del norte", que cuenta con casi 350 mil habitantes más una inmensa población flotante - los datos exactos no se tienen, pues son del cuestionado censo del 2012 - no tenga más que un par de librerías.

9. Comparativamente con Argentina, España, México y Colombia, los libros en Chile son caros, por una parte por tratarse de un mercado modesto y algo deprimido, lo que obliga a tirajes pequeños, aumentando los costos; por otra, debido al IVA del $19 \%$ a los libros, que es uno de los más altos no solo de América Latina sino del mundo. Los libros importados — que en las grandes librerías de la capital suelen 
ser la mayoría - se venden a un sobreprecio importante en relación al que tienen en sus países de origen. El problema del alto costo de los libros tiene que ver con la doble cuestión del arancel y del tiraje — por tanto, de la capacidad de las editoriales y de los circuitos de distribución para ampliar la oferta cuantitativamente-. ¿Cómo aumentamos la oferta nacional y cómo le quitamos barreras arancelarias a la vez, lo que sirve tanto a la oferta nacional como a la extranjera? ¿Pero, ayudaría? Sabemos, empero, que si un libro cuesta hoy 8.000 pesos y sin IVA queda en 6.480 pesos, ello no implica que vaya a ser más comprado por el público.

Y aquí viene ese otro y gran problema: el público. ¿Es que existe ese "público" esperando que bajen el IVA para consumir libros? ¿No hay acaso escasez de ciudadanos interesados en la lectura y también de consumidores para entretención y mero placer? El gran problema es cómo crear un mercado, cómo crear la "necesidad" del libro, una demanda que permita al sector crecer y no de-crecer.

10. A diferencia de lo ocurrido en países que han copado el mercado del libro hispanoparlante, Chile carece hasta la fecha de una política integral de fomento y desarrollo del sector. El Estado tiene cierta presencia, pero la misma es dispar, descoordinada e insuficiente. Desde el punto de vista del Estado, se requiere una coordinación permanente entre el Consejo del Libro, la DIBAM y el MINEDUC; también con la CORFO, PRO CHILE y la DIRAC. La Ley 19.227 del Libro de 1993 que creó el Consejo y el Fondo del Libro y la Lectura es una ley tímida, poco significativa si se la compara con las que rigen en Argentina, España, México y Colombia.

Aunque hoy, a diferencia de ayer, hay cierta reticencia al proteccionismo, cuando está en juego la educación y la inclusión social, más vale actuar. Al menos avanzar en varias de las medidas acordadas en la Política Nacional del Libro y la Lectura (véase más adelante referencias a este documento).

11. El Consejo del Libro, como la entidad estatal que asigna fondos públicos para el sector, presenta problemas. El fundamental es que se ha convertido en un mero administrador de fondos concursables, descuidando su labor como organismo que debiera pensar, articular y promover una estrategia para fomentar el libro y la lectura. Por otra parte, debido a su configuración corporativa — está conformado por representantes de la Sociedad de Escritores (SECH), Colegio de Bibliotecarios, Cámara Chilena del Libro y Asociación de Editores Independientes-, se corre el riesgo de que estos organismos gremiales defiendan de preferencia los proyectos presentados por sus propios asociados, lo que hace imprescindible velar por que no se produzca en este plano una suerte de cuoteo. El Consejo es además una editorial estatal oculta: los libros que financia o cofinancia a menudo no tienen ni distribución ni venta. También — tal como en el FONDART - hay distorsiones en los fondos asignados a provincias: debido a que la mayor parte de los proyectos regionales los gana la V Región, se ha producido una situación que desvirtúa el mecanismo de discriminación positiva que fue pensado para todas las regiones.

El diagnóstico anterior del sector del libro y la lectura merece atención en cada uno de los puntos planteados, lo que implica pensar, por una parte, una estrategia de fomento 
y desarrollo integral y de largo aliento. También, considerar que el Estado no es el único actor de políticas públicas, que deben involucrarse y participar como agentes en tales políticas el sector privado, la sociedad civil, los medios de comunicación e instituciones educativas como las universidades, lo que requiere pensar en estrategias e incentivos para que ello así ocurra.

Una buena base de futuro es la Política Nacional del Libro y la Lectura, consignada en un documento que emanó de los distintos actores del libro y del propio Consejo Nacional de la Cultura, y que contó además con el aval del ministro de Cultura de la época, José Weinstein, y también, en el año 2006, de la ministra Paulina Urrutia (Véase Politica Nacional del Libro y la Lectura, Santiago: Consejo Nacional del Libro, $1^{a}$ edición, 2006, $2^{a}$ edición, 2007). Documento que señala la necesidad de una nueva política para la lectura y el libro, una política sistémica e integral que considere todas las etapas de la cadena del libro. Se plantean allí un conjunto de medidas y objetivos en el plano del fomento de la lectura a través del libro (programa nacional continuo de fomento de la lectura; incrementar sustantivamente libros disponibles en bibliotecas públicas; subsidio para adquisiciones de libros chilenos científicos, académicos y técnicos; ampliación de redes de bibliotecas municipales y públicas; vincular la acreditación de universidades al cumplimiento de normas referidas a bibliotecas y reprografías; estimular convenios con medios de comunicación masivos para fortalecer la presencia del libro y la creación chilena). También, medidas para impulsar la edición, producción y comercialización de libros (beneficios tributarios en importaciones de libros; estudiar una posible rebaja del IVA a los libros; fomentar la publicación nacional de libros técnicos y científicos; bonificación postal tarifaria para impresos; favorecer con medidas fiscales y municipales a librerías dedicadas exclusivamente al comercio de libros; fortalecer el derecho de autor; instalar en Pro Chile un programa específico para favorecer la exportación de libros producidos en el país; fomentar el perfeccionamiento de profesionales relacionados a la cadena del libro). También, medidas para desarrollar la creación (potenciar concursos de edición de nuevas obras; reestructurar el Premio Nacional de Literatura, dándole un carácter anual y revisando la composición del jurado; generar instancias de capacitación para traductores; impulsar talleres y concursos literarios a nivel comunal; apoyar la creación de revistas y publicaciones de difusión y crítica literaria y cultural, también blogs y páginas web). Además, medidas para preservar y difundir el patrimonio literario, bibliográfico y documental (crear un Fondo de Adquisiciones para manuscritos y objetos literarios de valor patrimonial; ampliar la colección en soporte sonoro de la tradición oral y el patrimonio lingüístico de los pueblos originarios; crear línea de proyectos del Fondo del Libro y la Lectura que apoye iniciativas de conservación y restauración del patrimonio bibliográfico). Por último, se plantean medidas para mejorar la institucionalidad del libro (modificar la Ley 19.227 de 1993) en términos de examinar la estructura y funcionamiento del Consejo del Libro, explicitar una política de bibliotecas públicas, de fomento a la industria editorial nacional, de depósito legal y de la Ley de Propiedad Intelectual 17.336, de administración del ISBN coordinándose con el MINEDUC, para implementar un sistema permanente de estudios y estadísticas en el ámbito de la lectura y el libro. Hasta la fecha no se ha implementado prácticamente ninguna de estas 
propuestas, las que fueron discutidas por casi todos los actores del libro y ratificada por un organismo que pertenece al Estado y que vela por las políticas públicas en el sector. Por cierto, se trata de una propuesta que tendría que ser revisada y puesta al día, particularmente teniendo en cuenta las nuevas tecnologías y el libro digital.

Respecto a las políticas de otras instituciones, las universidades debieran jugar un rol muy importante, tanto en la conformación de bibliotecas adecuadas y al día como a través de editoriales universitarias, y también de librerías o puntos de venta, sobre todo en regiones. Es lamentable, por ejemplo, lo ocurrido con la Editorial Universitaria de la Universidad de Chile, editorial que hasta la década del 70 tuvo un rol destacado en el ámbito del libro, aportando a la bibliodiversidad no solo del país sino del continente, pero que luego, desde la intervención militar de la Universidad, y hasta hoy día, ha experimentado una decadencia constante. Resulta difícil entender que el rector actual haya premiado con una medalla rectoral a uno de los exrectores que en el pasado fue artífice de la decadencia económica y cultural de esa otrora prestigiosa editorial. Un ejemplo que contrasta es el de la Editorial UDP de la Universidad Diego Portales, la que a pesar de ser una universidad privada ha tenido una política de decidido apoyo a su editorial, la que en pocos años se ha convertido en una de las editoriales universitarias más importantes y exitosas del país. En la medida en que muchas de las alrededor de 60 universidades le dieran mayor apoyo al sector, podrían contribuir de forma significativa a la revitalización del libro y la lectura.

Por otra parte, hay una serie de medidas puntuales que podrían tomarse. Por ejemplo, el Fondo del Libro recibe como parte de los proyectos ejecutados una cantidad significativa de libros, los que muchas veces quedan en anaqueles empaquetados, o sin distribución: bien podrían adoptarse medidas para su circulación, distribución o venta al público. El Fondo del Libro es, en la práctica, una editorial estatal o semiestatal (por las coediciones), pero que como tal esta disfrazada: tal vez valdría la pena sincerarla, con el propósito de que los libros que se editan lleguen al público.

Hay en otros países medidas novedosas para incentivar la lectura, como la que se aplica en las cárceles de Brasil: un preso por leer un libro y hacer un resumen breve o una reseña tiene derecho a rebajar tres días de su pena. Si lee 50 libros al año puede disminuir su estadía en la cárcel por casi un año. Se incentiva la lectura, pero también se reconoce la importancia de la misma como autoeducación cultural y ciudadana. En México, con el apoyo del Estado y las gobernaciones, se han masificado desde hace años las bibliotecas de aula, bibliotecas abiertas y a libre disposición de los niños que se autocontrolan y se anotan al llevarse un libro a la casa. En Chile también hay, pero son pocas y, por lo general, los libros están en vitrinas y no a libre disposición de los alumnos. En Francia y en otros países opera la política del precio fijo a los libros, según algunos estudios se trata de un mecanismo que beneficia tanto a las librerías como a los lectores.

En fin, las posibilidades son infinitas, lo que importa es la voluntad política de llevar a cabo una estrategia integral y sistémica de fomento y desarrollo del libro y la lectura, una política que fortalezca la industria nacional del libro y que tienda a aumentar tanto la provisión como la demanda, aprovechando que el nuevo gobierno ha planteado un programa que tiene como ejes la educación y la inclusión social. Dos tareas ambiciosas y 
difíciles pero que, de cumplirse, traerían consigo la disminución de la distancia entre la visión idealizada del libro y su incidencia en la educación, entre la utopía y la realidad, entre la oferta y la demanda.

\section{BIBLIOGRAFÍA}

Henríquez, C., La aurora de Chile, Santiago, 13 febrero 1812.

Miers, J., Travels in Chile and La Plata, London, 1826 (la traducción es nuestra).

Sánchez, L. A., "Leyenda y realidad de la Editorial Ercilla", en Visto y vivido en Chile. Bitácora Chilena 1930-1970, Lima, 1975.

Sarmiento, D. F., "Bibliotecas Populares", 1866, en Obras Completas, tomo XXX, Buenos Aires, 1913.

Subercaseaux, B., Historia del libro en Chile. Desde la Colonia hasta el Bicentenario, Santiago: LOM, 3a edición, 2010. 